\title{
A tale of two MOOCs: How student motivation and participation predict learning outcomes in different MOOCs
}

\author{
Abi Brooker, Linda Corrin, Paula de Barba, Jason Lodge, Gregor Kennedy \\ University of Melbourne
}

\begin{abstract}
Recent scholarly discussions about massive open online courses (MOOCs) highlight pedagogical and practical issues that separate MOOCs from other learning settings, especially how theories of learning translate to MOOC students' motivation, participation, and performance. What is missing from these discussions is the purpose of the MOOC. We report a comparative study of two MOOCs that differ in educational purpose, but are similar in design. Our sample consisted of 983 students in a professional development MOOC, and 648 students in a MOOC focused on general interest. We first report differences between the two MOOCs, in terms of student demographics, achievement motivation, and participation. For each MOOC, we ran a two-stage regression analysis to determine the extent to which motivation variables (stage 1) and participation variables (stage 2) predicted performance. Patterns in demographic background and motivation differed in ways that were consistent with the MOOCs' purposes. Motivation and participation predicted performance, but this relationship differed between the two MOOCs and reflected the patterns of participation. Professional development motivation contributed to final grade in the professional development MOOC, but not the general interest MOOC. The findings have implications for how MOOC designers think about their target audience, and for students who aim for high final grades.
\end{abstract}

Massive open online courses (MOOCs) offer people the opportunity to study a variety of courses for a variety of reasons, including personal interest, professional development, and social networking. Likewise, the MOOCs themselves vary in intended purpose, in terms of how designers intend their MOOC to serve the needs of prospective students, especially in addressing intrinsic goals (e.g., general interest), or extrinsic goals (e.g., professional development). Recent research has examined the relationship between MOOC students' motivation, participation, and performance (DeBoer, Stump, Seaton, \& Breslow, 2013; Kizilcec \& Schneider, 2015; Milligan, Littlejohn, \& Margaryan, 2013; Xiong et al., 2015). What is unclear is how MOOCs with different intended purposes might impact students' motivations and participation, and how these subsequently impact performance. Understanding this relationship has important pedagogical and practical implications for future MOOC success.

In this paper, we report on a comparative study of two MOOCs that are similar in instructional design, in that they have similar learning environments (e.g., online platform, length of time, year) and use similar learning and instructional objects (e.g., discussion forums, video lectures, quizzes [Spector, Johnson, \& Young, 2014]); but they differ in the designer's intended purpose. First, we briefly consider the emerging literature on MOOCs, paying particular attention to the varied purposes of MOOCs, student motivation and participation. We examine the differences between the two MOOCs, and outline how these differences are - and are not - reflected in the student demographics, achievement motivation, and participation in the course. For each MOOC, we also report a two-stage regression analysis examining the extent to which achievement motivation variables (Stage 1) and participation variables (Stage 2) predicted performance (final grade) and whether different patterns of association exist for MOOCs that have different purposes.

\section{Background}

MOOCs emerged in 2008, offering access for anyone with an internet connection, to learning content and activities offered by disciplinary experts at little cost. MOOCs are similar to other forms of adult education in that they serve the purpose of helping adult learners to "achieve their full potential in life ... [and] apply knowledge and skills learned today to living more effectively tomorrow” (Knowles, 1970, p. 44). MOOCs are distinct from other online or face-to-face courses in that students are not limited by issues of location, language, timing, scope, or cost. MOOC students can choose to enrol in courses for a variety of reasons: to satisfy their personal interests, to further their career opportunities, to support a current course of study, or to meet new people (Kizilcec, Piech, \& Schneider, 2013). MOOCs have come under scrutiny in public discussions around practical issues such as attrition (Ho et al., 2015; Onah, Sinclair, \& Boyatt, 2014), access 
(Breslow et al., 2013), accreditation and certification (Daniel, 2012; Kocdar \& Aydin, 2015), and pedagogical issues such as instructional design (Spector, 2014) and the impact of pedagogy on students' motivation and participation (Castaño, Maiz, \& Garay, 2015). Discussions of design and pedagogy are particularly difficult considering the diversity of MOOCs (Conole, 2014) and a tendency of researchers to investigate MOOCs using a single case study approach (Reich, 2015).

While it is appropriate for scholars to scrutinise the practical and pedagogical issues associated with MOOCs, an equally important issue that is missing from these discussions is the impact of the MOOC's intended purpose. Intended purpose describes how designers intend the MOOC to serve the needs of prospective students. According to Knowles (1970), adult learners are typically problem-based learners who enrol in courses to address the problem of how to "live more effectively" (Knowles, 1970, p.44). Adult education can serve that need in two ways. It can serve intrinsic needs (e.g., improving understanding of a topic, further a love of learning), or extrinsic needs (e.g., career advancement, professional development). Although not impossible, extrinsically motivated students will struggle to achieve their goals in a course serving students' intrinsic needs, and vice versa. Therefore, adult courses that serve intrinsic or extrinsic needs (or both) must make that intention clear (in their title, or in their advertisements) in order to attract appropriate learners, and ultimately be effective. As much as MOOCs can be considered courses for adult learners, they too adhere to this practice. For instance, the intended purpose of a MOOC might serve extrinsic needs in that it develops students' professional skills as educators, such as North Carolina State University's Digital Learning Transition MOOC for K-12 teachers (Kleinman, Wolf, \& Frye, 2013). Alternatively, the intended purpose might serve intrinsic needs in that it aims to satisfy students' interest in poetry or philosophy, such as University of Pennsylvania’s Modern \& Contemporary American Poetry and Yale University's Philosophy: Death MOOC.

We do not suggest that extrinsic (professional development) and intrinsic (general interest) purposes are mutually exclusive. Many MOOCs meet both purposes. For example, Belanger and Thornton (2013) describe equally important dual purposes of Duke University's Bioelectricity MOOC, which was “aimed at advanced undergraduate or early graduate students in science and engineering, but the course was open to any student regardless of background" (p. 3). We are interested in highlighting that MOOCs often have different intended purposes. As such, it is of interest to clarify MOOCs' intended purposes, determine whether those purposes attract students with different motivations, and subsequently, whether that motivation impacts upon how students participate in the MOOC and their learning outcomes.

It is likely that MOOCs with specific intended purposes attract people with similar needs and motivations for enrolling. Although there are no studies to our knowledge that systematically test this relationship, students' varied reasons for enrolling in MOOCs have been well documented, including obtaining skills and knowledge, personal challenge, supplementing another course, and career advancement (Breslow et al., 2013; Kizilcec \& Schneider, 2015; Littlejohn, Hood, Milligan, \& Mustain, 2016; Xiong et al., 2015). There is still a need to understand how MOOC students' achievement motivation contributes to their online learning experiences and performance.

\section{Achievement motivation in MOOCs}

Theories of achievement motivation have contributed considerably to our understanding of student learning in traditional face-to-face classrooms (Eccles \& Wigfield, 1995). In general, these theories propose that students tend to perform better if they make substantial effort (Pintrich \& Schunk, 2002), feel in control (Perry, Hladkyj, Pekrun, \& Pelletier, 2001), perceive the importance of what they are learning (Eccles \& Wigfield, 1995), or are interested in the topic (Renninger, Hidi, \& Krapp, 1992). Underlying these theories is the complementary relationship between students' motivations and their level of participation in a course (Ainley, 1993). Further, students with strong performance goals (i.e., goals oriented toward obtaining recognition, such as grades) are more likely to participate in an activity and demonstrate higher levels of achievement that those with weak performance goals (Harackiewicz, Barron, Pintrich, Elliot \& Thrash, 2002). This pattern is likely to translate to MOOC students' experiences, as adult learners are typically performance-oriented in their learning (Knowles, 1970). Further, considering the well-known issues of high attrition rates and lack of participation on MOOCs (Ho et al., 2015; Kizilcec, Piech, \& Schneider, 2013), the current study focuses on better understanding students' adoption of performance goals in MOOCs. 
Achievement motivation is also associated with students' perceptions of the value and usefulness of their course (Eccles \& Wigfield, 1995). As suggested above, prospective students first perceive that usefulness through the advertised intended purpose of the course. For example, motivation tends to increase if extrinsically motivated students perceive that the content of a course will contribute to career advancements. Courses perceived as serving intrinsic purposes are also beneficial, as general interest in a topic has been related to students' decision-making around their learning, their effort, and their likelihood to re-engage with the same topic in the future (Hidi \& Renninger, 2006).

In online learning environments, motivation has a positive impact on students' participation and performance (Giesbers, Rienties, Tempelaar \& Gijselaers, 2014; Rakes \& Dunn, 2010) and goal setting behaviour (Cisel, 2014; Wilkowski, Deutsch \& Russell, 2014). In their study with online graduate students, Rakes and Dunn (2010) found that higher levels of motivation were associated with lower levels of procrastination. Wilkowski et al. (2014) demonstrated that student goals at the beginning of a MOOC predicted almost half of the variance in their participation throughout the course. Similar advances have been made in MOOC research of student motivation in the past 2 years, with researchers identifying different patterns of motivation that are related to participation (e.g., Littlejohn et al., 2016; Milligan et al., 2013), or final grade (e.g., Castaño et al., 2015), or retention (Xiong et al., 2015). These studies are unveiling relationships that provide preliminary support for theories of motivation and learning, however most rely on students' retrospective comments about their motivation (e.g., Castaño et al., 2015; Milligan et al., 2013). A more reliable approach is to measure students' motivation and goals at specific points in time, such as when they enrol or at the beginning of the course (Kizilcec \& Schneider, 2015; Xiong et al., 2015), or at various points throughout the course (de Barba, Kennedy \& Ainley, 2016). Kizilcec and Schneider (2015) found that different motivations to pursue a MOOC tend to lead to different patterns of participation during the course. Xiong et al. (2015) demonstrated a relationship between motivation upon enrolment, engagement, and retention in the MOOC. De Barba et al. (2016) found that motivation influenced and was influenced by participation, with both direct and indirect effect on performance.

\section{MOOC participation}

One of the most common approaches to researching MOOCs is to identify different patterns of student learning behaviour and participation. These studies typically focus on students' access to (or avoidance of) assessment tasks and video lectures (Adams, Yin, Vargas Madriz, \& Mullen, 2014; Kizilcec et al., 2013), and discussion forums (Cheng, Paré, Collimore, \& Joordens, 2011; Huang, Dasgupta, Ghosh, Manning, \& Sanders, 2014). Kizilcec et al. (2013) identified four patterns of participation with video lectures (engagement, auditing, sampling, and disengagement). The three latter patterns reflected a form of engagement that might otherwise be dismissed as disengagement in face-to-face learning environments, or pathways to attrition in online learning environments.

This study addresses two important gaps in scholarly discussions about MOOCs. First, although there is increasing attention on the relationship between students' motivation, goals, participation and performance in MOOCs, studies focus on single MOOC case studies and report qualitative analysis of retrospective data about motivation and goals (Littlejohn et al., 2016; Milligan et al., 2013) or binary outcome measures such as retention and dropout (Xiong et al., 2015). Our study addresses this gap in two ways. We systematically analyse two MOOCs separately to show how similarities and differences in this relationship might emerge. We record students' motivation for enrolling early in the course and measure performance by the student's final grade. Second, practical and pedagogical discussions around MOOCs overlook the implications of the different intended purpose of MOOCs. Distinguishing between MOOCs of different purposes can benefit both discussions by identifying alignment between the MOOC designer's intentions about the purpose of the course, and prospective students' motivations. We address this gap by demonstrating differences in student cohorts, participation, and outcome for two MOOCs that differ in educational purpose.

\section{The current study}

The current study investigates the relationship between student motivation, participation, and performance for two MOOCs that differ in intended purpose, and are similar in instructional design. The two MOOCs were Assessment and Teaching Skills in the Twenty First Century MOOC (ATS21C), which focused on professional development, and Animal Behaviour MOOC (AB), which stimulated students' general interest in animals. 
Two preliminary research questions sought to determine whether and how the two MOOCs differed in terms of their student cohorts' motivation and participation in MOOC activities. These preliminary questions were:

- Do MOOCs with different educational purposes attract similar or different student cohorts?

- How similar or different are patterns of participation within these MOOCs?

Following preliminary analyses, two main research questions were used to investigate the relationship between motivation, participation, and performance for the two MOOCs that differed in purpose. These research questions were:

- To what extent do students' motivations influence their participation and, subsequently, their performance (final grade) in the MOOC?

- How do these relationships differ across MOOCs with different educational purposes?

\section{Method}

\section{Participants}

The sample consisted of 1,631 students enrolled in one of the two MOOCs: 983 from ATS21C and 648 from AB. All participants in the sample met two inclusion criteria. They (a) remained active throughout the last weeks of their MOOC, and (b) completed a survey at the beginning of their course about their demographic information and motivations for enrolling in the MOOC. These criteria allowed us to focus on students who had experienced the majority of the course as intended by the course convenors. The criteria limited our study sample to $48 \%$ of all ATS21C students and $29 \%$ of all AB students. Table 1 shows the similar patterns of demographic information for the study sample in comparison to all survey respondents (respondents were $98 \%$ of the ATS21C cohort, and $92 \%$ of the AB cohort).

Table 1

Demographic information for two MOOC cohorts and samples

\begin{tabular}{|c|c|c|c|c|c|}
\hline & \multicolumn{2}{|c|}{ \% ATS21C } & \multicolumn{2}{|c|}{$\% \mathrm{AB}$} \\
\hline & & $\begin{array}{c}\text { Survey } \\
\text { respondents }\end{array}$ & Current sample & $\begin{array}{c}\text { Survey } \\
\text { respondents }\end{array}$ & $\begin{array}{l}\text { Current } \\
\text { sample }\end{array}$ \\
\hline$n$ & & 1989 & 983 & 2046 & 648 \\
\hline \multicolumn{6}{|c|}{ Age: } \\
\hline & $0-24$ & $7.0 \%$ & 5.2 & 34.3 & 25.2 \\
\hline & $25-44$ & 58.6 & 55.1 & 46.5 & 48.3 \\
\hline & $45-64$ & 32.6 & 37.7 & 15.0 & 21.0 \\
\hline & $65+$ & 1.7 & 2.0 & 3.6 & 5.6 \\
\hline \multicolumn{6}{|c|}{ Gender: } \\
\hline & Male & 28.8 & 31.4 & 26.1 & 30.1 \\
\hline & Female & 69.9 & 67.5 & 71.4 & 67.4 \\
\hline \multicolumn{6}{|c|}{ Academic background: } \\
\hline & Partial HS or less & 0.5 & 0.1 & 6.5 & 4.8 \\
\hline & HS diploma / some college & 4.9 & 3.0 & 26.1 & 18.5 \\
\hline & Assoc dip / BA & 36.6 & 37.1 & 38.9 & 38.3 \\
\hline & Masters / PhD & 57.6 & 59.3 & 28.3 & 38.3 \\
\hline
\end{tabular}

Also shown in Table 1, the two MOOC samples differed from each other in their demographic information. The distribution of age was more dispersed among AB students than ATS21C students. A higher proportion of older students were enrolled in ATS21C, and a higher proportion of younger students were enrolled in AB. Academic background also differed, as a higher proportion of ATS21C students had completed postgraduate studies, and a higher proportion of $\mathrm{AB}$ had completed high school. These differences are consistent with the profiles that we might expect: students who enrol in MOOCs for general interest may be any age (younger than 18 to older than 64), whereas people who enrol in MOOCs for professional development are likely to be of professional age with higher qualifications (25 - 64). 


\section{Materials and measures}

The similar instructional design of the two MOOCs allowed us to more specifically focus on differences in purpose, and differences in motivation. Both MOOCs were offered in 2014 and delivered by the University of Melbourne in partnership with Coursera. They both ran for a similar amount of time (6-8 weeks) and released learning materials in a linear weekly format. They were broadly similar in learning activities including assessments (written assignments and quizzes), video lectures (between 10 and 14 minutes long), and discussion forums (approximately 14 in each). One notable difference was the use of conceptual links and hyperlinks between video lectures and forums in ATS21C. Other differences included the number of learning outcomes, number of video lectures, number of quizzes, and assessment weighting.

ATS21C's purpose was to offer professional development. The aim of the course, stated on its Coursera website, was to give teachers new skills to address the challenges of teaching in the twenty-first century. It was expected that students were already working in professional educator roles. The MOOC's 19 learning outcomes were divided among the 6 weeks of the course so that each week had distinct learning objectives. The 33 video lectures were connected to the forum threads dedicated to specific issues via hyperlinks and voting polls. These were embedded in the videos and prompted students to discuss their opinions further. In addition to two written assignments that were worth $90 \%$ combined, there were three quizzes worth $10 \%$ of the overall grade.

AB's purpose was to provide general understanding of animal behaviour for those who were interested. On its Coursera website, the aim of the course was to allow students to explore natural selection and sexual selection in animals. Students were not expected to have prior knowledge of the topic. The five learning outcomes were applied across all weeks of the course. The 44 video lectures were connected to the discussion forums via hyperlink, but unlike the ATS21C MOOC, no prompts were given in the videos to access the forums. The seven quizzes were worth $60 \%$ of the overall grade and the remaining $40 \%$ was allocated to two written assignments.

MOOC participation was measured by how often students accessed three activities: quizzes, video lectures, and discussion forums. We included all three activities in acknowledgement of the varied ways in which students engage with MOOCs (Kizilcec et al., 2013; Perna et al., 2013), and because all three were central activities within the two MOOCs. Participation was measured by the total count for each unique activity, that is, the number of times a student accessed a particular activity excluding any repeated access. This measure emphasises the breadth of each students' participation across the entire MOOC. Participation with quizzes was measured by the total number of unique quizzes attempted. Participation with video lectures was measured by the total number of unique videos for which the student clicked play (streamed), and as a separate variable, the total number of unique videos that the student downloaded. Participation with discussion forums was measured by the total number of times a student: viewed the discussion forum, made a thread (new conversation), created a post, created a comment (a reply to post), and voted on existing posts or comments. These measures are well-accepted indicators of students' participation in MOOCs (Kizilcec et al., 2013; Perna et al., 2013; Xiong et al., 2015).

Achievement motivation was measured by two variables collected from the survey: students' reasons for enrolling and students' goals. The survey included a list of seven reasons for enrolling in the MOOC, including: "It's free", "Supplementing other college or university class", and "I am geographically isolated from educational institutions". Respondents could choose as many of the reasons as applied to them. We focused on two items that reflected the broader intended purposes of the MOOCs: serving intrinsic needs ("General interest in [course name]") and serving extrinsic needs ("Professional development"). This allowed us to focus the analysis on alignment (or misalignment) between the intended purpose of the MOOC and students' reasons for enrolling. A binary code was used for responses to these items $(0=$ motivation not present, 1 = motivation present). 
Students could choose one of four responses to indicate their performance goals prior to undertaking the course: watch videos without trying assignments; try some assignments but not necessarily all assignments; try all assignments and earn a statement of accomplishment; or try all assignments and earn a statement with distinction. Responses were coded into a single performance goal variable with three mutually exclusive categories: $0=$ does not intend to pass (i.e., combining "watch videos ...", and "try some assignments ...”), 1 = intends to pass (i.e., earn a statement of accomplishment), or 2 = intends to earn a statement with distinction.

Performance was measured by students’ final grade. For both MOOCs, the final grade comprised results from quizzes and written assessments. The distribution of grades for both MOOC samples ranged from 0 to $100 \%$.

\section{Procedure}

Students who enrolled in either MOOC were invited to complete the survey, answering questions about their demographic information and motivation. The survey opened in the week preceding the course and remained available throughout the course. The majority of students completed the survey during the first week of the course (ATS21C: 72\%; AB: 81\%). Data logs of students' participation, final grades, and survey responses were collected and de-identified by Coursera as per the university's Human Research Ethics Committee’s approval for this study (HREC: 1340710.1).

\section{Results}

\section{Preliminary analysis}

The preliminary analyses sought to compare the two MOOCs in terms of students' motivation and participation. Table 2 presents these distributions for the study sample. The same information for the full MOOC cohorts are also displayed, only as further confirmation of the representativeness of the sample. The samples represented their larger cohorts in terms of motivation, but not participation.

Addressing the first preliminary question, the two MOOCs attracted different types of student, in terms of their motivations and goals. Chi-square analyses revealed differences between the two MOOC groups' motivations to enrol in their course, with adjusted standardised residuals $(\hat{e})$ of greater magnitude than \pm 2.0 showing statistical significance. The significant chi-square statistics comparing the two sample's distributions are shown under Table 2. A higher proportion of ATS21C students $(83.0 \%, \hat{e}=18.6)$ than AB students (38.3\%, $\hat{e}=-18.6)$ were motivated by professional development. A higher proportion of $\mathrm{AB}$ students $(85.2 \%, \hat{e}=6.4)$ than ATS21C students $(71.5 \%, \hat{e}=-6.4)$ were motivated by general interest. Regarding goals, a higher proportion of ATS21C students $(46.6 \%, \hat{e}=3.6)$ than AB students $(37.6 \%, \hat{e}=-$ 3.6) intended to pass, and a higher proportion of ATS21C students $(31.4 \%, \hat{e}=2.4)$ than AB students $(25.9 \%, \hat{e}=-2.4)$ aimed to earn a distinction.

Addressing the second preliminary question, the patterns of participation in the two MOOCs differed for quizzes, video lectures, and discussion forums. Although similar proportions of students in the two MOOCs accessed quizzes, of those who did so, ATS21C students accessed a higher proportion of their quizzes than AB students $(F(1,1511)=23.86, p<.0001)$. Higher proportions of ATS21C students $(93.4 \%, \hat{e}=4.3)$ than AB students (87.2\%, $\hat{e}=-4.3)$ streamed their MOOC's video lectures. Lower proportions of ATS21C students $(76.6 \%, \hat{e}=-2.2)$ than $\mathrm{AB}$ students $(81.2 \%, \hat{e}=2.2)$ viewed the discussion forums. Among those who used forums, ATS21C students viewed their discussion forums more frequently than AB students, made more threads $(F(1,1278)=5.72, p<.02)$, posts $(F(1,1278)=25.30, p<.0001)$, comments $(F(1$, $1278)=13.13, p<.0001)$, and votes $(F(1,1278)=20.22, p<.0001)$. 
Table 2

Motivation and participation of two MOOC cohorts and samples

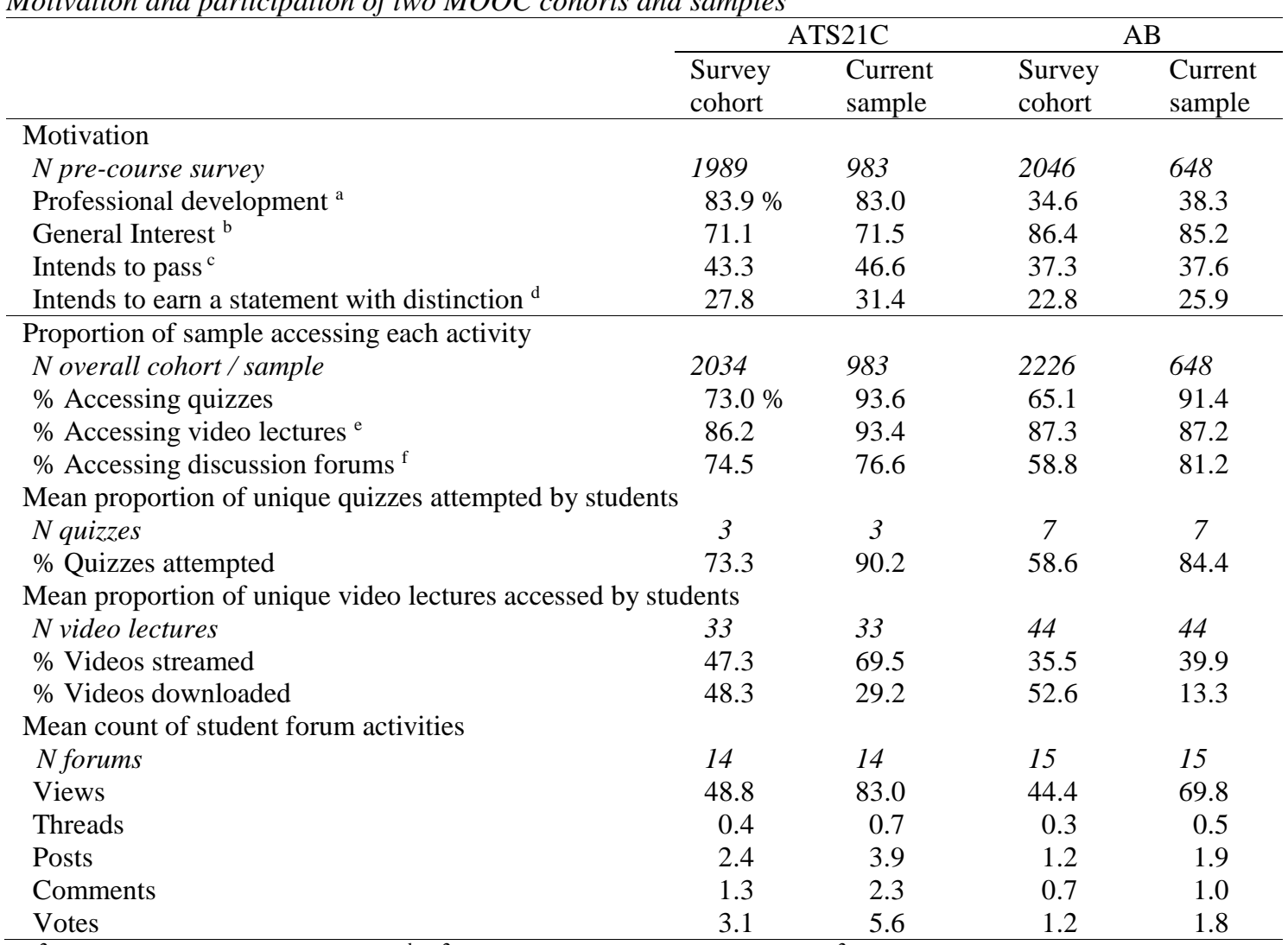

${ }^{\mathrm{a}} X^{2}(1,1631)=344.70, p<.001 ;{ }^{\mathrm{b}} X^{2}(1,1631)=41.14, p<.001 ;{ }^{\mathrm{c}} X^{2}(1,1626)=12.91, p<.001 ;$

${ }^{\mathrm{d}} X^{2}(1,1626)=5.86, p<.05 ;{ }^{\mathrm{e}} X^{2}(1,1631)=18.17, p<.001 ;{ }^{\mathrm{f}} X^{2}(1,1631)=4.82, p<.05$.

These findings depict two MOOC contexts that can be distinguished from each other in patterns of students' motivation and participation. Considering the differences in these contexts, we deem it appropriate to continue the main analyses for each MOOC separately, and compare findings for the two only in the discussion.

\section{Main analyses}

The main analyses sought to determine the relationship between student motivation, participation, and performance for each of the two MOOCs. Addressing the first research question, a two-stage stepwise multiple regression was conducted to determine the extent to which motivation and participation variables predicted performance (final grade). We ran this analysis for each MOOC separately to address the second research question. In both regressions, three motivation variables were entered at stage 1 of the analysis and eight participation variables were entered at stage 2 .

\section{ATS21C MOOC}

Table 3 shows the correlations between the motivation variables, participation variables and final grade for ATS21C, along with the mean score and standard deviation for each item. On average, ATS21C students intended to pass, and their mean final grade was 56.64. All but one of the independent variables (i.e., not general interest) had a significant, moderate or weak correlation with final grade. The strongest correlations were between the independent variables related to forum activity. 
Table 3

Correlations between ATS21C students' motivation, participation, and final grade $(n=983)$

\begin{tabular}{|c|c|c|c|c|c|c|c|c|c|c|c|c|}
\hline & 1 & 2 & 3 & 4 & 5 & 6 & 7 & 8 & 9 & 10 & 11 & 12 \\
\hline 1. Final grade & & .01 & $.11^{\mathrm{a}}$ & $.35^{\mathrm{a}}$ & $.68^{\mathrm{a}}$ & $.31^{\mathrm{a}}$ & $-.09^{b}$ & $.11^{\mathrm{a}}$ & $.16^{\mathrm{a}}$ & $.16^{\mathrm{a}}$ & $.09^{\mathrm{b}}$ & $0.13^{\mathrm{a}}$ \\
\hline $\begin{array}{l}\text { 2. General } \\
\text { interest }\end{array}$ & & & .02 & $.06^{\mathrm{c}}$ & .02 & -.01 & .03 & $-.07^{c}$ & .01 & -.03 & -.05 & -0.05 \\
\hline $\begin{array}{l}\text { 3. Professional } \\
\text { development }\end{array}$ & & & & $.15^{\mathrm{a}}$ & $.08^{\mathrm{b}}$ & $.06^{\mathrm{c}}$ & .00 & .05 & .05 & $.08^{\mathrm{b}}$ & $.06^{\mathrm{c}}$ & $0.06^{c}$ \\
\hline $\begin{array}{l}\text { 4. Performance } \\
\text { goal }\end{array}$ & & & & & $.33^{\mathrm{a}}$ & .03 & .01 & $.06^{\mathrm{c}}$ & $.13^{\mathrm{a}}$ & $.17^{\mathrm{a}}$ & $.07^{\mathrm{b}}$ & 0.04 \\
\hline $\begin{array}{l}\text { 5. Quiz } \\
\text { attempts }\end{array}$ & & & & & & $.29^{\mathrm{a}}$ & $-.18^{a}$ & $.09^{\mathrm{b}}$ & $.15^{\mathrm{a}}$ & $.15^{\mathrm{a}}$ & $.09^{\mathrm{b}}$ & $0.11^{\mathrm{a}}$ \\
\hline $\begin{array}{l}\text { 6. Video } \\
\text { streams }\end{array}$ & & & & & & & $-.45^{a}$ & $.14^{\mathrm{a}}$ & $.17^{\mathrm{a}}$ & $.17^{\mathrm{a}}$ & $.12^{\mathrm{a}}$ & $0.15^{\mathrm{a}}$ \\
\hline $\begin{array}{l}\text { 7. Video } \\
\text { downloads }\end{array}$ & & & & & & & & -.04 & -.04 & -.03 & -.04 & -0.02 \\
\hline 8. Forum views & & & & & & & & & $.32^{\mathrm{a}}$ & $.64^{\mathrm{a}}$ & $.57^{\mathrm{a}}$ & $0.42^{\mathrm{a}}$ \\
\hline $\begin{array}{l}\text { 9. Forum } \\
\text { threads }\end{array}$ & & & & & & & & & & $.63^{\mathrm{a}}$ & $.40^{\mathrm{a}}$ & $0.38^{\mathrm{a}}$ \\
\hline 10. Forum posts & & & & & & & & & & & $.70^{\mathrm{a}}$ & $0.51^{\mathrm{a}}$ \\
\hline $\begin{array}{l}\text { 11. Forum } \\
\text { comments } \\
\text { 12. Forum votes }\end{array}$ & & & & & & & & & & & & $0.47^{\mathrm{a}}$ \\
\hline Mean & 56.6 & 0.7 & 0.8 & 1.1 & 2.5 & 21.4 & 10.2 & 63.8 & 0.6 & 3.5 & 2.1 & 5.0 \\
\hline$S D$ & 33.8 & 0.5 & 0.4 & 0.7 & 0.9 & 11.8 & 13.7 & 162.4 & 1.5 & 7.5 & 6.8 & 16.5 \\
\hline
\end{tabular}

At stage 1 of the ATS21C stepwise multiple regression, the motivation variables contributed significantly to the model, $F(3,976)=46.37, p<.0001$, and accounted for approximately $12 \%$ of variance in students' final grades $\left(R^{2}=.353\right.$, Adjusted $\left.R^{2}=.122\right)$. Final grade was primarily predicted by performance goal and to a lesser extent professional development. With the addition of the participation variables in stage 2, professional development was no longer a significant predictor. Stage 2 accounted for $50 \%$ of variance in students' final grades $\left(R^{2}=.507\right.$, Adjusted $\left.R^{2}=.510\right)$, and this change in $R^{2}$ was significant $F(8,968)=$ 93.73, $p<.0001$. Quiz access was the strongest predictor, followed by video lectures streamed, performance goal and video lectures downloaded. The raw and standardised regression coefficients, structure coefficients and adjusted $R^{2}$ for each stage are shown in Table 4.

Table 4

ATS21C MOOC stepwise regression of motivation and participation onto final grade $(n=983)$

\begin{tabular}{|c|c|c|c|c|c|c|}
\hline Model & Adjusted $R^{2}$ & $r$ & $\mathrm{~b}$ & $S E-\mathrm{b}$ & $\mathrm{B}$ & $\begin{array}{l}\text { Structural } \\
\text { coefficient }\end{array}$ \\
\hline 1 & .122 & & & & & \\
\hline Constant ${ }^{\mathrm{a}}$ & & & 35.23 & 3.13 & & \\
\hline General interest & & .013 & -.58 & 2.24 & -0.01 & .02 \\
\hline Prof. development ${ }^{\mathrm{b}}$ & & .109 & 5.38 & 2.73 & 0.06 & .15 \\
\hline Performance goal ${ }^{\mathrm{a}}$ & & .348 & 15.84 & 1.41 & 0.34 & .49 \\
\hline 2 & .501 & & & & & \\
\hline Constant $^{\mathrm{a}}$ & & & -23.90 & 3.42 & & \\
\hline General interest & & .013 & -0.23 & 1.70 & -0.00 & .02 \\
\hline Prof. development & & .109 & 2.60 & 2.07 & -0.03 & .15 \\
\hline Performance goal ${ }^{a}$ & & .348 & 6.52 & 1.15 & 0.14 & .49 \\
\hline Quiz access $^{{ }^{a}}$ & & .681 & 23.01 & 0.98 & 0.59 & .96 \\
\hline Video view $^{\text {a }}$ & & .311 & 0.48 & 0.08 & 0.17 & .44 \\
\hline Video download ${ }^{\text {a }}$ & & -.091 & 0.22 & 0.06 & 0.09 & -.13 \\
\hline Forum views & & .111 & 0.01 & 0.01 & 0.02 & .16 \\
\hline Forum threads & & .158 & 0.39 & 0.68 & 0.02 & .22 \\
\hline Forum posts & & .164 & -0.03 & 0.19 & -0.01 & .23 \\
\hline Forum comments & & .093 & -0.09 & 0.16 & -0.02 & .13 \\
\hline Forum votes & & .134 & 0.08 & 0.06 & 0.04 & .19 \\
\hline
\end{tabular}

${ }^{\mathrm{a}} p<.0001 ;{ }^{\mathrm{b}} p<.05$ 


\section{AB MOOC}

Table 5 shows the correlations between the motivation variables, participation variables and final grade for $\mathrm{AB}$, along with the mean and standard deviation for each variable. On average, $A B$ students intended to pass. Their mean final grade was 50.19. Most of the independent variables were significantly, but weakly, correlated with final grade. Quiz access was strongly correlated with final grade; and general interest, videos streamed, and videos downloaded were not correlated with final grade. As with ATS21C, the strongest correlations appeared between the independent variables related to forum activity.

Table 5

Correlations between $A B$ students' motivation, participation, and final grade $(n=648)$

\begin{tabular}{|c|c|c|c|c|c|c|c|c|c|c|c|c|c|}
\hline & & 1 & 2 & 3 & 4 & 5 & 6 & 7 & 8 & 9 & 10 & 11 & 12 \\
\hline 1. & Final grade & & .00 & $.16^{\mathrm{a}}$ & $.35^{\mathrm{a}}$ & $.84^{\mathrm{a}}$ & -.02 & -.03 & $.29^{\mathrm{a}}$ & $.26^{\mathrm{a}}$ & $.29^{a}$ & $.19^{a}$ & $0.22^{\mathrm{a}}$ \\
\hline 2. & $\begin{array}{l}\text { General } \\
\text { interest }\end{array}$ & & & $-.16^{a}$ & -.03 & .01 & -.02 & -.02 & .04 & $-.08^{c}$ & -.06 & -.05 & -0.03 \\
\hline 3. & $\begin{array}{l}\text { Professional } \\
\text { development }\end{array}$ & & & & $.31^{\mathrm{a}}$ & $.15^{\mathrm{a}}$ & -.02 & $.13^{\mathrm{a}}$ & -.03 & $.07^{\mathrm{c}}$ & .06 & .02 & 0.01 \\
\hline 4. & $\begin{array}{l}\text { Performance } \\
\text { goal }\end{array}$ & & & & & $.28^{\mathrm{a}}$ & -.02 & .03 & $.11^{\mathrm{b}}$ & $.13^{\mathrm{a}}$ & $.16^{\mathrm{a}}$ & $.10^{\mathrm{b}}$ & $0.13^{\mathrm{a}}$ \\
\hline 5. & Quiz access & & & & & & -.03 & -.03 & $.21^{\mathrm{a}}$ & $.18^{\mathrm{a}}$ & $.20^{\mathrm{a}}$ & $.12^{\mathrm{a}}$ & $0.15^{\mathrm{a}}$ \\
\hline 6. & Video view & & & & & & & .04 & -.06 & $-.11^{b}$ & $-.09^{b}$ & $-.08^{a}$ & $-.11^{\mathrm{b}}$ \\
\hline 7. & $\begin{array}{l}\text { Video } \\
\text { download }\end{array}$ & & & & & & & & .03 & $-.08^{c}$ & $.07^{\mathrm{c}}$ & $.07^{\mathrm{c}}$ & 0.02 \\
\hline 8. & $\begin{array}{l}\text { Forum } \\
\text { views }\end{array}$ & & & & & & & & & $.45^{\mathrm{a}}$ & $.59^{\mathrm{a}}$ & $.50^{\mathrm{a}}$ & $0.52^{\mathrm{a}}$ \\
\hline 9. & $\begin{array}{l}\text { Forum } \\
\text { threads }\end{array}$ & & & & & & & & & & $.86^{\mathrm{a}}$ & $.68^{\mathrm{a}}$ & $0.52^{\mathrm{a}}$ \\
\hline 10. & Forum posts & & & & & & & & & & & $.78^{\mathrm{a}}$ & $0.63^{\mathrm{a}}$ \\
\hline $\begin{array}{l}11 . \\
12 .\end{array}$ & $\begin{array}{l}\text { Forum } \\
\text { comments } \\
\text { Forum votes }\end{array}$ & & & & & & & & & & & & $0.62^{\mathrm{a}}$ \\
\hline $\mathrm{Me}$ & & 50.2 & 0.9 & 0.4 & 0.9 & 5.4 & 15.3 & 6.0 & 56.4 & 0.4 & 1.5 & 0.8 & 1.5 \\
\hline$S D$ & & 32.4 & 0.4 & 0.5 & 0.8 & 2.4 & 17.1 & 14.0 & 129.9 & 1.1 & 4.1 & 3.4 & 5.4 \\
\hline
\end{tabular}

At stage 1 of the $\mathrm{AB}$ stepwise multiple regression, the motivation variables contributed significantly to the model, $F(3,642)=30.34, p<.0001$, and accounted for $12 \%$ of variance in students' final grades $\left(R^{2}=\right.$ .124 , Adjusted $\left.R^{2}=.120\right)$. Final grade was primarily predicted by performance goal. With the addition of the participation variables, stage 2 accounted for $74 \%$ of variance in students' final grades $\left(R^{2}=.744\right.$, Adjusted $R^{2}=.739$ ), and this change in $R^{2}$ was significant $F(8,634)=191.66, p<.0001$. Quiz access was the strongest predictor, followed by performance goal and forum views. The raw and standardised regression coefficients, structure coefficients and adjusted $R^{2}$ for each stage are shown in Table 6 . 
Table 6

$A B M O O C$ stepwise regression of motivation and participation onto final grade $(n=648)$

\begin{tabular}{|c|c|c|c|c|c|c|c|}
\hline \multicolumn{2}{|c|}{ Model } & Adjusted $R^{2}$ & $r$ & $\mathrm{~b}$ & $S E-\mathrm{b}$ & $\mathrm{B}$ & $\begin{array}{c}\text { Structural } \\
\text { coefficient }\end{array}$ \\
\hline \multirow[t]{5}{*}{1} & & .124 & & & & & \\
\hline & Constant $^{\mathrm{a}}$ & & & 34.59 & 3.58 & & \\
\hline & General interest & & .004 & 2.19 & 3.41 & .02 & .00 \\
\hline & Prof. development & & .160 & 4.14 & 2.62 & .06 & .19 \\
\hline & Performance goal ${ }^{\mathrm{a}}$ & & .347 & 13.60 & 1.61 & .33 & .40 \\
\hline \multirow[t]{13}{*}{2} & & .739 & & & & & \\
\hline & Constant $^{\mathrm{a}}$ & & & -12.03 & 2.40 & & \\
\hline & General interest & & .004 & 0.08 & 1.87 & .00 & .00 \\
\hline & Prof. development & & .160 & 0.76 & 1.45 & .01 & .19 \\
\hline & Performance goal ${ }^{a}$ & & .347 & 4.19 & 0.91 & .10 & .40 \\
\hline & Quiz access $^{\mathrm{a}}$ & & .843 & 10.34 & 0.29 & .78 & .98 \\
\hline & Video views & & -.022 & 0.02 & 0.04 & .01 & -.03 \\
\hline & Video downloads & & -.027 & -0.04 & 0.05 & -.02 & -.03 \\
\hline & Forum views ${ }^{b}$ & & .293 & 0.02 & 0.01 & .07 & .34 \\
\hline & Forum threads & & .264 & 1.19 & 1.21 & .04 & .31 \\
\hline & Forum posts & & .294 & 0.64 & 0.41 & .08 & .34 \\
\hline & Forum comments & & .187 & -0.55 & 0.32 & -.06 & .33 \\
\hline & Forum votes & & .224 & 0.12 & 0.17 & .02 & .26 \\
\hline
\end{tabular}

${ }^{\mathrm{a}} p<.0001 ;{ }^{\mathrm{b}} p<.01$

\section{Discussion}

This study set out to investigate the relationship between student motivation, participation and performance for two MOOCs that differed in intended purpose and were similar in instructional design. The two MOOCs attracted different student cohorts, in terms of students' age, academic background, motivation for enrolling in the MOOC and goal orientation. Student motivation, goal orientation and participation predicted performance, and this relationship differed across the two MOOCs.

\section{The two MOOCs attracted different cohorts}

The differences in the two MOOC's cohorts are consistent with other research in terms of different demographic profiles (Christensen et al., 2013; Zhenghao et al., 2015), and MOOC students’ motivations and goals (Kleinman et al., 2013). Similar to Zhenghao et al. (2015), a substantial proportion of the students in our study were young adults who had completed or were completing tertiary studies. The majority of ATS21C students were motivated by the extrinsic motivation of professional development, as are students in other professional development MOOCs targeting teachers (Kleinman et al., 2013). The close accord between the MOOCs intended purpose and students' motivation is consistent with Eccles and Wigfield's (1995) assertion that student's perceptions of the value of the course before enrolment impacts upon on their motivations for enrolling in the course. However, neither MOOC was exclusively associated with one type of motivation. Some ATS21C students were motivated by general interest, and some AB students were motivated by professional development. This is consistent with contemporary views more generally about achievement motivation, which have moved from a binary view of motivation toward a pluralistic view (Wentzel, 1993).

\section{The two MOOCs had different patterns of participation}

With the exception of quizzes and proportion of students using the discussion board, ATS21C students were generally more active in their participation than AB students. This difference might be explained by aspects of the design, in terms of the relationship between various learning activities (e.g., Castaño et al., 2015; Spector, 2014). For instance, the higher levels of participation in ATS21C video lectures, and more frequent use of the discussion forums in ATS21C than AB might be explained by the live polls and prompts to use the forums in ATS21C's video lectures. It is likely that these polls and prompts encouraged students to access forums more often, and consequently, forum discussions about video lecture content encouraged other students to view the video lectures. In contrast, the lack of shepherding between video lectures (or any other activity or assessment) in $\mathrm{AB}$ may mean that students who participated in the AB forums were 
doing so of their own volition, and that volition could reasonably reflect a higher level of engagement with the course as a whole.

\section{Reasons for enrolling did not contribute to final grade}

Although professional development had some impact on students' participation, and was more prevalent as a motivation for ATS21C students than AB students, it did not contribute to performance in the overall regressions for either MOOC. One explanation is that even if professional development is important for accessing and completing a course, its impact on performance is mediated by participation. That is, students motivated by professional development might be motivated to pass the course without being motivated to participate beyond minimal requirements. These findings are similar to a previous study in which the impact of motivation toward the course on final grade was mediated by participation (de Barba et al., 2016).

Our findings only partially support other studies investigating the relationship between MOOC students' reasons for enrolling and participation or performance (e.g., Xiong et al., 2015). Xiong et al. (2015) found that motivation (extrinsic and intrinsic) contributed to engagement and to students' final outcome. This is the pattern that we were expecting to find in our study, but which we found only for intrinsically motivated students (those motivated by general interest) in the general interest MOOC (AB). The differences between the two studies might be due to slightly different measures used. For instance, Xiong et al. defined academic outcome as a binary measure of retention versus dropout, whereas we measured outcome with the continuous variable of their final grade. With different (but related) measures, it is difficult to speculate about what these different patterns might mean. Further studies using the same measures as out study or as Xiong et al.'s study, would go a long way towards confirming, refuting, or explaining our different patterns.

\section{Performance goal and participation contributed to final grade}

The finding that higher performance goals (intending to earn a statement with distinction) contributed to students' final grade is consistent with research on the impact of performance goals in face-to-face learning environments (Harackiewicz et al., 2002), adult education (Knowles, 1970) and online learning environments (Cisel, 2014; Giesbers et al., 2014). Students who identified early on that they wanted to achieve a distinction continued toward that goal throughout the MOOC regardless of their motivation to enroll, and regardless of their participation patterns in the MOOC. This effect persisted regardless of the MOOC’s purpose.

The finding that participation with quizzes was the strongest predictor of final grade (for both MOOCs) is not surprising, considering that the quizzes contributed to the final grade and provided formative feedback about the students' progress. That video participation contributed to final grade in ATS21C, and forum participation contributed to final grade in $\mathrm{AB}$, are in line with other research arguing for the important role of video lectures in MOOCs (Adams et al., 2014; Zahn, Krauskopf, Kiener, \& Hesse, 2014) and research identifying a positive association between forum views and final grade (Cheng et al., 2011).

\section{Implications and conclusion}

The relationship between design, and our focus on intended purpose, warrants attention. The importance of good design for facilitating students' participant cannot be understated for any course, let alone any MOOC. For instance, the small differences in in some learning objects within the two MOOCs (e.g., the use of voting polls and prompts to use the ATS21C forums) in our study reasonably explained some differences in students' participation. Good design encompasses an array of considerations, ranging from identifying various learning objects and the relationships between those objects (e.g., Spector, 2014) to ensuring constructive alignment between learning outcomes, assessments and activities (e.g., Biggs, 1996). Our attempt to compare two MOOCs similar in instructional design was not an attempt to dismiss design, but an attempt to highlight a less often observed but still important element of design: the intended purpose of the MOOC. Clearly, other design considerations continue to deserve attention in discussions about pedagogical benefits of MOOCs. We hope that this research adds to those discussions the importance of considering the intended purpose of the MOOC.

With this in mind, our findings indicate that the intended purpose of the MOOC appears to attract particular kinds of students, and students' ongoing motivations and design interact to influence their final outcome. 
That the MOOCs attracted students from different backgrounds has implications for practical and strategic issues of accreditation and monetisation, namely, that MOOC providers need to consider the life circumstances of their targeted audiences that might impact their decision to enrol. That the students varied in motivation has implications for MOOC designers who are concerned with issues of student retention, engagement, or outcome. Specifically, designers would be well advised to consider how specific learning objects might meet the various needs of their targeted audience. For instance, active and engaging forums that are not directly assessable might be valuable for students motivated by general interest, or to those motivated by professional development and see value in networking and building professional relationship, but may be of little value to auto-didactic learners or students only interested in earning a certificate for a specific professional development indicator. While reasonable, these assertions require more careful testing within the MOOC context.

Our findings also have implications for MOOC students, and those implications fit with a well-versed message for students who want high grades: aim to do well from the beginning of the course and participate in the range of activities on offer. Of course, there are other outcomes that MOOC students might be aspiring toward, such as achieving mastery goals, personal or social goals, or achieving goals beyond the MOOC. Had we focused on any of these other outcomes instead of final grade, factors such as performance goal and participation might not have mattered as much.

A final implication of this research is that understanding the students' perspective is vital for understanding the benefits of MOOCs. Enormous amounts of data are collected from MOOCs about students' online activities (e.g., when, where, and how often they participate). However, mapping students' online behavior in MOOCs does not equate to mapping their learning. Interpretations of these data are enhanced by understanding the students' reasons for their participation. We recommend that researchers interested in understanding learning in MOOCs consider the students' perspective (motivations, goals, and interpretations of activities) and how those perspectives might change over time. We expect that students' explanations of their behaviour in MOOCs will offer insights that reflect key principles of adragogy and pedagogy (e.g., Knowles, 1970). We also recommend that researchers consider the broader context of the MOOC (intended purpose) and the impact that this has on students' experiences. We anticipate that further work in this area will establish clear associations between the designer's intended purpose of the MOOC and the benefits that students receive from participating. These are not novel considerations, but, as the results of this study reinforce, these are pivotal factors to consider when developing a MOOC and when interrogating the benefits of MOOCs as learning environments.

There are two elements of our approach that could be considered potential limitations, and therefore require explanation: our inclusion criteria and the complexities of comparing MOOCs. Regarding our inclusion criteria, we limited our sample to those who were active in the final weeks of the course and who therefore achieved a final grade from $0-100$. Our limited sample might suggest that we cannot generalise our findings to the large number of students who drop out of MOOCs. However, we were most interested in students who had experienced the whole course as course convenors had intended to be experienced. As such, our findings reflect the learning outcomes that align with traditional theories of learning that were developed in situations where students attended the entire class and were assessed on their performance (e.g., Eccles \& Wigfield, 1995). Our samples were representative of their respective MOOC cohorts (or, at least, the survey respondents) in terms of demographic information and motivation. Any future studies investigating how different MOOCs influence the relationship between student motivation, participation and dropout would benefit from including a wider sample of MOOC students than the sample used in our research.

Regarding the second limitation, the fact that MOOCs can differ in intended purpose, design, content, cohort demographics, and context, makes it difficult to systematically compare across multiple MOOCs. We were interested in the different intended purposes of MOOCs, so we made every effort to ensure that the two MOOCs in our analysis were similar in other components of design: they shared the same platform, were hosted by the same University in the same year, and were reasonably similar in length, types of learning activities and assessments. The different profiles of student demographics, especially age and academic achievement, were consistent with the intended purpose of each MOOC, and were therefore not considered to be problematic. 
In summary, this study furthers scholarly understanding of MOOC students' motivation, participation, and performance by acknowledging the role of the MOOC's intended purpose: that MOOCs with different purposes attract cohorts of students with different patterns of motivation; and provide contexts that change the nature of the relationship between student motivation, participation, and outcome. The intended purpose of the MOOC thus requires closer attention in discussions about practical and pedagogical issues associated with MOOCs. We look forward to studies that systematically test and further this argument, especially studies that compare courses with similar purposes and different designs and provide a closer look to the role of motivation across a MOOC.

\section{References}

Adams, C., Yin, Y., Vargas Madriz, L. F., \& Mullen, C. S. (2014). A phenomenology of learning large: the tutorial sphere of xMOOC video lectures. Distance Education, 35(2), 202-216. https://doi.org/10.1080/01587919.2014.917701

Ainley, M. D. (1993). Styles of engagement with learning: Multidimensional assessment of their relationship with strategy use and school achievement. Journal of Educational Psychology, 85(3), 395-405.

Barba, P. D., Kennedy, G. E., \& Ainley, M. D. (2016). The role of students' motivation and participation in predicting performance in a MOOC. Journal of Computer Assisted Learning, 32(3), 218-231.

Belanger, Y., \& Thornton, J. (2013). Bioelectricity: A quantitative approach -- Duke University's first MOOC. Retrieved from https://dukespace.lib.duke.edu/dspace/handle/10161/6216

Biggs, J. (1996). Enhancing teaching through constructive alignment. Higher education, 32(3), 347-364. http://dx.doi.org/10.1037/0022-0663.85.3.395

Breslow, L., Pritchard, D. E., DeBoer, J., Stump, G. S., Ho, A. D., \& Seaton, D. T. (2013). Studying learning in the worldwide classroom: Research into edX's first MOOC. Research \& Practice in Assessment, 8(1), 13-25.

Castaño, C., Maiz, I., \& Garay, U. (2015). Design, motivation and performance in a cooperative MOOC Course. Comunicar, 22(44), 19-26. http://dx.doi.org/10.3916/C44-2015-02

Cheng, C. K., Paré, D. E., Collimore, L.-M., \& Joordens, S. (2011). Assessing the effectiveness of a voluntary online discussion forum on improving students' course performance. Computers \& Education 56(1), 253 - 261. https://doi.org/10.1016/j.compedu.2010.07.024

Christensen, G., Steinmetz, A., Alcorn, B., Bennett, A., Woods, D., \& Emanuel, E. J. (2013). The MOOC phenomenon: Who takes massive open online courses and why? Retrieved from https://papers.ssrn.com/sol3/papers.cfm?abstract_id=2350964.

Cisel, M. (2014, March). Analysing completion rates in the first French xMOOC. Paper presented at the European MOOCs Stakeholders Summit, Lausanne, Switzerland.

Conole, G. (2014). A new classification schema for MOOCs. The International Journal for Innovation and Quality in Learning, 2(3), 65-77.

Daniel, J. (2012). Making sense of MOOCs: Musings in a maze of myth, paradox and possibility. Journal of Interactive Media in Education, 2012(1), 1-20. https://doi.org/10.5334/2012-18

DeBoer, J., Stump, G. S., Seaton, D., \& Breslow, L. (2013, June). Diversity in MOOC students' backgrounds and behaviors in relationship to performance in 6.002 x. In Proceedings of the Sixth Learning International Networks Consortium Conference, Massachusetts, USA.

Eccles, J. S., \& Wigfield, A. (1995). In the mind of the actor: The structure of adolescents' achievement task values and expectancy-related beliefs. Personality and Social Psychology Bulletin 21(3), 215225. https://doi.org/10.1177/0146167295213003

Giesbers, B., Rienties, B., Tempelaar, D., \& Gijselaers, W. (2014). A dynamic analysis of the interplay between asynchronous and synchronous communication in online learning: The impact of motivation. Journal of Computer Assisted Learning, 30(1), 30-50. https://doi.org/10.1111/jcal.12020

Harackiewicz, J. M., Barron, K. E., Pintrich, P. R., Elliot, A. J., \& Thrash, T. M. (2002). Revision of achievement goal theory: Necessary and illuminating. Journal of Educational Psychology, 94(3), 638645. https://doi.org/10.1037/0022-0663.94.3.638

Hidi, S., \& Renninger, K. A. (2006). The four-phase model of interest development. Educational Psychologist, 41(2), 111-127. https://doi.org/10.1207/s15326985ep4102_4

Ho, A. D., Chuang, I., Reich, J., Coleman, C. A., Whitehill, J., Northcutt, C. G., ... \& Petersen, R. (2015). HarvardX and MITx: Two years of open online courses. Fall 2012-Summer 2014. Retrieved from https://ssrn.com/abstract $=2586847$ 
Huang, J., Dasgupta, A., Ghosh, A., Manning, J., \& Sanders, M. (2014). Superposter behavior in MOOC forums. Proceedings of the first ACM conference on Learning@ scale conference, Atlanta, GA, 117126. https://doi.org/10.1145/2556325.2566249

Kizilcec, R. F., Piech, C., \& Schneider, E. (2013). Deconstructing disengagement: Analyzing learner subpopulations in massive open online courses. Proceedings of the $3^{\text {rd }}$ International Conference on Learning Analytics and Knowledge, Leuven, Belgium, 170-179. https://doi.org/10.1145/2460296.2460330

Kizilcec, R. F., \& Schneider, E. (2015). Motivation as a lens to understand online learners: Toward datadriven design with the OLEI scale. ACM Transactions on Computer-Human Interaction, 22(2), Article 6, 1-24. https://doi.org/10.1145/2699735

Kleinman, G., Wolf, M. A., \& Frye, D. (2013). The digital learning transition MOOC for educators: exploring a scalable approach to professional development. Retrieved from http://miblendonline.pbworks.com/w/file/fetch/76438373/MOOC-Ed.pdf

Knowles, M. S. (1970). The modern practice of adult education: From pedagogy to adragogy. Eaglewood Cliffs, NJ: Cambridge Ault Education.

Kocdar, S., \& Aydin, C. H. (2015, April). Quality assurance and accreditation of MOOCs: Current issues and future trends. Paper presented at Open Education Global Conference 2015, Alberta, Canada. Retrieved from http://conference.oeconsortium.org/2015/wp-content/uploads/2015/02/OECPAPER.docx

Littlejohn, A., Hood, N., Milligan, C., \& Mustain, P. (2016). Learning in MOOCs: Motivations and selfregulated learning in MOOCs. The Internet and Higher Education, 29, 40-48. https://doi.org/10.1016/j.iheduc.2015.12.003

Milligan, C., Littlejohn, A., \& Margaryan, A. (2013). Patterns of engagement in connectivist MOOCs. MERLOT Journal of Online Learning and Teaching, 9(2), 149-159.

Onah, D. F., Sinclair, J., \& Boyatt, R. (2014). Dropout rates of massive open online courses: Behavioural patterns. Proceeding of EDULEARN14, Barcelona, Spain, 5825-5834.

Perna, L., Ruby, A., Boruch, R., Wang, N., Scull, J., Evans, C., \& Ahmad, S. (2013, December). The life cycle of a million MOOC users. Paper presented at MOOC Research Initiative Conference, Arlington, Texas.

Perry, R. P., Hladkyj, S., Pekrun, R. H., \& Pelletier, S. T. (2001). Academic control and action control in the achievement of college students: A longitudinal field study. Journal of Educational Psychology, 93(4), 776-789. https://doi.org/10.1037/0022-0663.93.4.776

Pintrich, P. R., \& Schunk, D. H. (2002). Motivation in education: Theory, research and applications. Upper Saddle River, NJ: Merrill Prentice Hall.

Rakes, G. C., \& Dunn, K. E. (2010). The impact of online graduate students' motivation and selfregulation on academic procrastination. Journal of Interactive Online Learning, 9(1), 78-93.

Reich, J. (2015). Rebooting MOOC research. Science, 347 (6217), 34-5. https://doi.org/10.1126/science.1261627

Renninger, K. A., Hidi, S., \& Krapp, A. (1992). The role of interest in learning and development. Hillsdale, NJ: Erlbaum. https://doi.org/10.1007/s11423-011-9195-4

Spector, J. M. (2014). Remarks on MOOCS and mini-MOOCS. Educational Technology Research and Development, 62(3), 385-392. https://doi.org/10.1007/s11423-014-9339-4

Spector, J. M., Johnson, T. E., \& Young, P. A. (2014). An editorial on research and development in and with educational technology. Educational Technology, Research and Development, 62(1), 1-12.

Wentzel, K.R. (1993). Social and academic goals at school: Motivation and achievement in context. In M. L Maehr \& P. R. Pintrich (Eds.), Advances in motivation and achievement (Vol. 7, pp. 185-212). Greenwich: JAI Press.

Wilkowski, J., Deutsch, A., \& Russell, D. M. (2014, March). Student skill and goal achievement in the mapping with google MOOC. Proceedings of the first ACM conference on Learning@ scale conference, Atlanta, USA, 3-10. https://doi.org/10.1145/2556325.2566240

Xiong, Y., Li, H., Kornhaber, M. L., Suen, H. K., Pursel, B., \& Goins, D. D. (2015). Examining the relations among student motivation, engagement, and retention in a MOOC: A structural equation modeling approach. Global Education Review, 2(3), 23-33. 
Zahn, C., Krauskopf, K., Kiener, J., \& Hesse, F. (2014). Designing video for massive open online education: Conceptual challenges from a learner-centred perspective. Proceedings of European MOOC Stakeholder's Summit, Lausanne, 160-167. Retrieved from https://www.researchgate.net/profile/Anja_Lorenz/publication/263543544_Open_Online_Courses_in the context_of higher_education_an_evaluation_of_a_German_cMOOC/links/54941c560cf2e1b60 95f97bc.pdf\#page $=160$

Zhenghao, C., Alcorn, B., Christensen, G., Eriksson, N., Koller, D., \& Emanuel, E. J. (2015). Who’s benefiting from MOOCs and why. Harvard Business Review Digital Articles, 9/22/2015, 2-8. Retrieved from https://hbr.org/2015/09/whos-benefiting-from-moocs-and-why

Corresponding author: Abi Brooker, brookera@unimelb.edu.au

Australasian Journal of Educational Technology @ 2018.

Please cite as: Brooker, A., Corrin, L., de Barba, P, Lodge, J., \& Kennedy, G. (2018). A tale of two MOOCs: How student motivation and participation predict learning outcomes in different MOOCs. Australasian Journal of Educational Technology, 34(1), 73-87. https://doi.org/10.14742/ajet.3237 